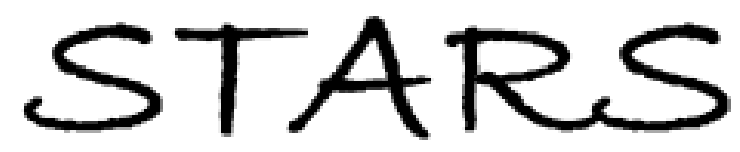

University of Central Florida

STARS

$1-1-2003$

\title{
Fabrication of an infrared antenna-coupled microbolometer linear array using chrome as a mask
}

\author{
Michael A. Gritz \\ University of Central Florida \\ Irina Puscasu \\ David Spencer \\ Glenn D. Boreman \\ University of Central Florida
}

Find similar works at: https://stars.library.ucf.edu/facultybib2000

University of Central Florida Libraries http://library.ucf.edu

This Editorial Material is brought to you for free and open access by the Faculty Bibliography at STARS. It has been accepted for inclusion in Faculty Bibliography 2000s by an authorized administrator of STARS. For more information, please contact STARS@ucf.edu.

\section{Recommended Citation}

Gritz, Michael A.; Puscasu, Irina; Spencer, David; and Boreman, Glenn D., "Fabrication of an infrared antenna-coupled microbolometer linear array using chrome as a mask" (2003). Faculty Bibliography 2000s. 3787.

https://stars.library.ucf.edu/facultybib2000/3787

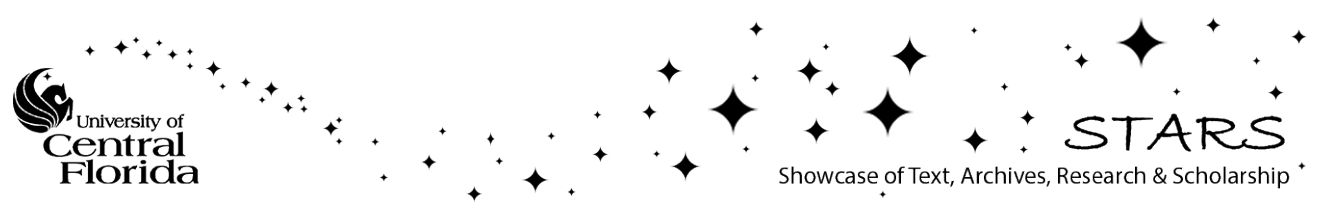


Fabrication of an infrared antenna-coupled microbolometer linear array using chrome as a mask

Michael A. Gritz, Irina Puscasu, David Spencer, and Glenn D. Boreman

Citation: Journal of Vacuum Science \& Technology B: Microelectronics and Nanometer Structures Processing, Measurement, and Phenomena 21, 2608 (2003); doi: 10.1116/1.1629714

View online: https://doi.org/10.1116/1.1629714

View Table of Contents: https://avs.scitation.org/toc/jvn/21/6

Published by the American Institute of Physics 


\title{
SHOP NOTES
}

These are "how to do it" papers. They should be written and illustrated so that the reader may easily follow whatever

instruction or advice is being given.

\section{Fabrication of an infrared antenna-coupled microbolometer linear array using chrome as a mask*}

\author{
Michael A. Gritz ${ }^{\mathrm{a})}$ \\ School of Optics/CREOL, University of Central Florida, 4000 Central Florida Blvd., Orlando, \\ Florida 32816-2700 \\ Irina Puscasu \\ Ion Optics Inc., 411 Waverly Oaks Rd., Suite 144, Waltham, Massachusetts 02452 \\ David Spencer \\ Cornell Nanofabrication Facility, Cornell University, Ithaca, New York 14853-540 \\ Glenn D. Boreman \\ School of Optics/CREOL, University of Central Florida, 4000 Central Florida Blvd., Orlando, \\ Florida 32816-2700
}

(Received 4 March 2003; accepted 6 October 2003; published 26 November 2003)

[DOI: $10.1116 / 1.1629714]$

\section{INTRODUCTION}

Conventional bolometers have been used as thermal detectors for infrared (IR) radiation by making use of the change of the bolometer resistance with an increase in the temperature either by absorbing the irradiation directly or absorbing the heat power by a radiation absorber. ${ }^{1}$ For the case of an antenna-coupled microbolometer, the irradiation power is then received by the antenna. Then the induced current on the antenna passes through the microbolometer, which causes a change in the resistance of the bolometer from Joule heating. The advantages of antenna-coupled microbolometers are their room temperature operation as well as their tunablity for wavelength and polarization response. Antenna-coupled microbolometers and metal-oxide-metal detectors have been demonstrated in the infrared at wavelengths near $10 \mu \mathrm{m} \cdot{ }^{2-4}$ Work has been done in fabricating a thin-film niobium antenna-coupled microbolometer element using spiral antennas fabricated on a silicon $(\mathrm{Si})$ substrate. ${ }^{5}$ This work suggested a method of fabricating a bolometric detector using dipole elements.

In this article, we present our work on the fabrication process developed for a dipole antenna-coupled microbolometer linear array. The array was fabricated with a direct write electron beam (e-beam) lithography tool. We have demonstrated a process which uses a reactive ion etcher (RIE) with chromium as a mask for the fabrication of the aluminum dipole antennas. A traditional lift-off process yielded aluminum dipole antenna arms with widths of $200 \mathrm{~nm}$. Our pro-

\footnotetext{
* No proof corrections received from author prior to publication.

a) Author to whom correspondence should be addressed; electronic mail: mgritz@creol.ucf.edu
}

cess allowed for a single layer of resist to be used, which enhances our linewidth control to $90 \mathrm{~nm}$ for the dipole antenna arms.

\section{DESIGN}

Results from previous work indicated that the effective wavelength of our system was $2.5 \mu \mathrm{m} .{ }^{6}$ In order to obtain a linear array with a beam maximum at $90^{\circ}$, the spacing between elements should be an integer multiple of the effective wavelength. Therefore, we designed a linear array with a center-to-center spacing of $5 \mu \mathrm{m}$ between dipole antennas. The receivers were fabricated on a 3 in. silicon $(\mathrm{Si})$ substrate, which was coated on both sides with $200 \mathrm{~nm}$ of silicon dioxide $\left(\mathrm{SiO}_{2}\right)$. Previous work has found that a high resistivity substrate in the range of $2335-3941 \Omega \mathrm{cm}$ yielded a $52 \%$ power transmission. ${ }^{7}$ Therefore, the resistivity of the substrate was chosen to be in this range. The $\mathrm{Si}$ wafers were polished on both sides to allow for illumination from either side of the substrate. The linear array consisted of 15 dipole elements with a center-to-center spacing of $5 \mu \mathrm{m}$ and with a dipole length of $10 \mu \mathrm{m}$. Figure 1 displays a scanning electron micrograph (SEM) of three elements within our linear array.

\section{FABRICATION AND RESULTS}

The linear arrays were fabricated at the Cornell Nanofabrication Facility using a Cambridge/Leica (Leica Microsystems-www.leica-microsystems.com) Electron Beam Micro-Fabricator (EBMF) 10.5 e-beam lithography system. The field that was used to write the devices was $819.2 \mu \mathrm{m}$. On each $10 \mathrm{~mm} \times 10 \mathrm{~mm}$ Si chip ten devices were 


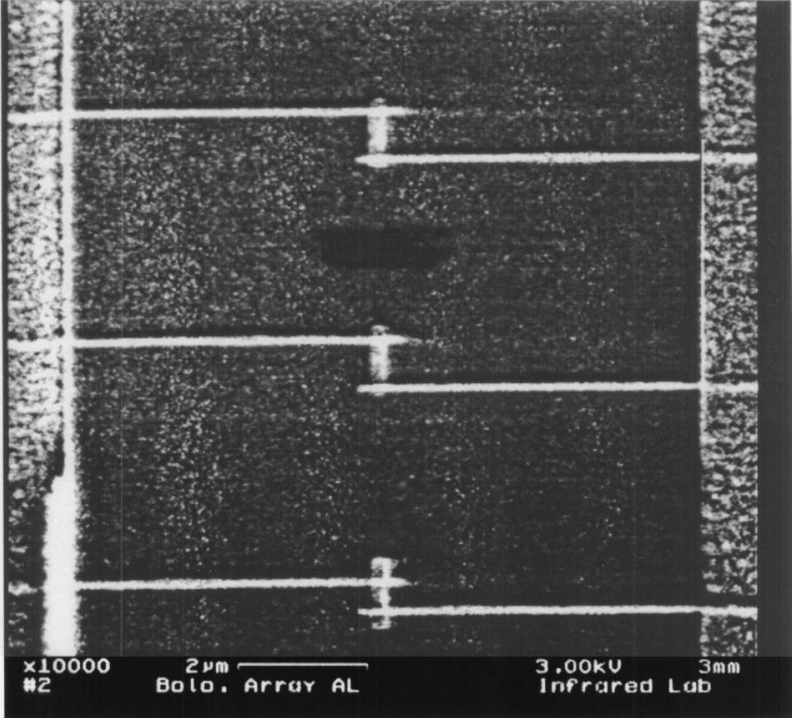

FIG. 1. SEM micrograph of three of the dipole elements in the linear array of antenna-coupled niobium microbolometers.

written with a $730 \mu \mathrm{m}$ center-to-center spacing. A single element detector was fabricated on each chip in order to ensure that all elements of the receivers were functioning properly. There were four separate layers which were fabricated in the following order:

(1) gold alignment marks using a bilayer resist lift-off process;

(2) aluminum antenna arms using a chromium mask aluminum etching process;

(3) aluminum bond pads using a bilayer resist lift-off process; and

(4) niobium detectors using a bilayer lift-off process.

The alignment marks were made of gold to provide good contrast between the marks and $\mathrm{Si}$ substrate for detection by the EBMF backscatter detector.

The first step in the fabrication process was to write a set of alignment marks. Both local and global alignment marks were written. The global marks were used to correct for any rotation errors while loading the substrates into the chuck, while the local marks were used to correct for any stage drift when moving from field to field. By using the two sets of alignment marks, extremely precise alignment was possible. In Ref. 8, when $250 \mathrm{~nm}$ of Au was used, the overlay accuracy was better than $25 \mathrm{~nm}$.

The lift-off technique is a common processing technique used among e-beam lithographers. In a lift-off process the thickness of the metal will determine the type of resist profile employed. For applications that require a thickness greater than $50 \mathrm{~nm}$, a bilayer lift-off process is used. A bilayer liftoff process uses two layers of resist. The bottom layer is poly(methylmethacrylate and methacrylic acid) (PMMAMAA) [see Fig. 2(a)]. The PMMA-MAA layer has a larger undercut because of its higher sensitivity. ${ }^{9}$ The second layer is poly(methylmethacrylate) PMMA. If e-beam evaporation

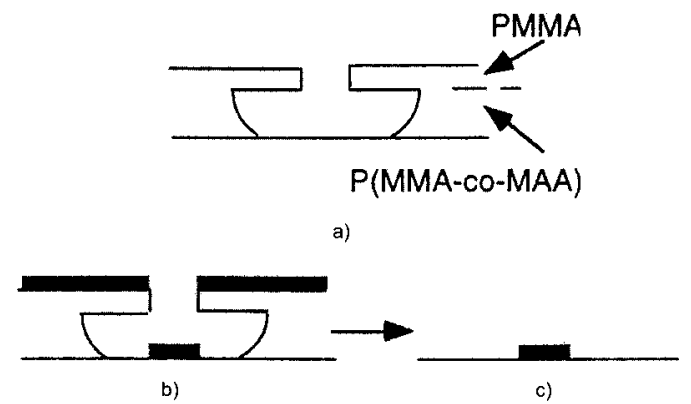

FIG. 2. Diagram of a bilayer e-beam resist profile. (a) PMMA is spun on top of the copolymer PMMA-MAA. (b) After the metal is e-beam evaporated. (c) The resist is then dissolved in methylene chloride or acetone.

is used to deposit the metal, then the PMMA will be the ultimate resolution of the entire system [see Fig. 2(b)]. E-beam evaporation is considered to be a point source, which implies that the material will fall onto the resist and substrate. This will provide a clean separation of the material allowing for a solvent such as methylene chloride, which dissolves the resist, to undercut the resist [see Fig. 2(c)].

The alignment marks were fabricated on a $3 \mathrm{in}$. Si substrate using a bilayer resist profile. First PMMA-MAA was spun on the wafer at $3500 \mathrm{rpm}$. The substrates were baked on a hot plate set to $170{ }^{\circ} \mathrm{C}$ for $10 \mathrm{~min}$ to remove any solvents. Using an interferometer, the resist thickness was measured at $561 \mathrm{~nm}$. After the resist thickness was measured, the second layer was spun onto the substrates. For this layer, PMMA was spun onto the substrates at $3500 \mathrm{rpm}$. Next, the substrates were baked on a hot plate set to $170^{\circ} \mathrm{C}$ for $10 \mathrm{~min}$. This yielded a total resist thickness of $710 \mathrm{~nm}$. The alignment marks were then exposed in the e-beam writer at a beam current of $30 \mathrm{nA}$ with a dose of $200 \mu \mathrm{C} / \mathrm{cm}^{2}$. The wafer was developed in Methyl Isobutyl Ketone: Isopropanol (MIBK:IPA) 1:1 for $2 \mathrm{~min}$. After development the substrates were rinsed with isopropanol and dried with $\mathrm{N}_{2}$. The next step was to remove any unwanted resist, which may have been left behind after the development but not seen under an optical microscope. The presence of such a thin layer of resist was found to lead to bad contacts between elements in our bolometers. The thin layer of resist was removed by oxygen plasma in a barrel etcher. ${ }^{10}$ This was done each time immediately after the development of the substrates. Then a 10-nm-thick adhesion layer of titanium and a 250-nm-thick layer of gold were evaporated onto the substrate. The lift-off was carried out using methylene chloride to remove the resist.

The next step in the fabrication process was to fabricate the antenna arms. For our process, the wafer was first coated with $120 \mathrm{~nm}$ of aluminum using a thermal evaporator [see Fig. 3(a)]. Then a single layer of PMMA was spun onto the substrates at $1700 \mathrm{rpm}$ [see Fig. 3(b)]. The advantage of using a single layer of resist is there is less forward scattering in the resist, thus enhancing line width control. Next the substrates were baked on a hot plate set to $170{ }^{\circ} \mathrm{C}$ for $10 \mathrm{~min}$. This yielded a total resist thickness of $140 \mathrm{~nm}$. The antenna arms were then exposed in the e-beam writer in positive 


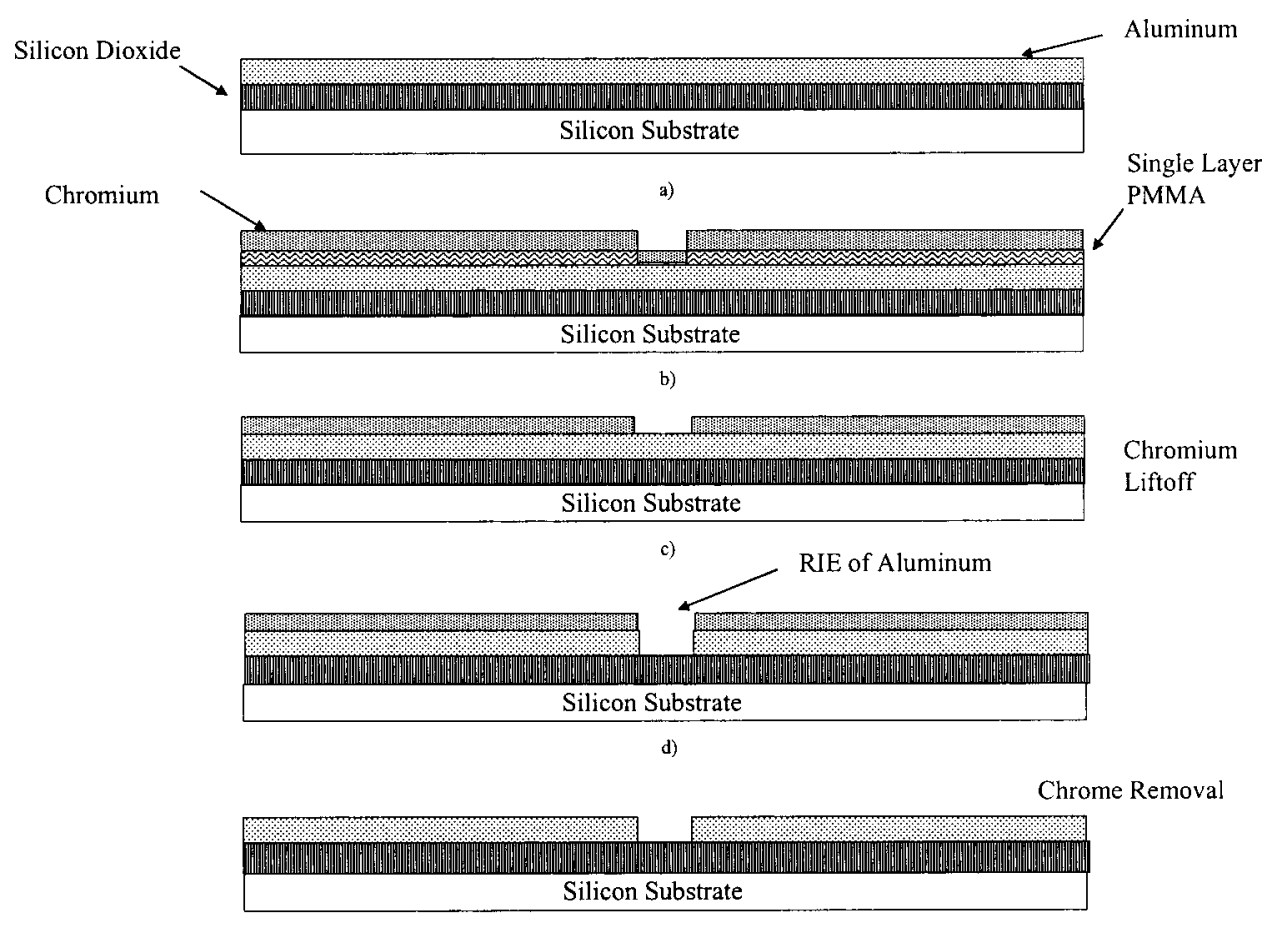

FIG. 3. Details of the fabrication process to fabricate a linear array of antenna-coupled microbolometers.

e)

resist at a beam current of $0.50 \mathrm{nA}$ with a line dose of 4.4 $\mu \mathrm{C} / \mathrm{cm}$. The wafer was developed in MIBK:IPA 1:3 for 2 min. After development, the substrates were rinsed with isopropanol and dried with $\mathrm{N}_{2}$, and an oxygen plasma etch was performed in a barrel etcher for $1 \mathrm{~min}$. Then a 23 -nm-thick layer of chromium was thermally evaporated onto the substrate [see Fig. 3(c)]. The lift-off was carried out using methylene chloride. Next a RIE was used with $1.5 \mathrm{sccm} \mathrm{Cl} 2,40$ sccm $\mathrm{BCl}_{3}$, and $20 \mathrm{sccm} \mathrm{CH}_{4}$ to remove the aluminum [see Fig. 3(d)]. The chromium in our system served as an etch mask. The final step is to remove the chromium [see Fig. 3(e)]. It was found that chrome etchant also removed aluminum, so a resist strip using $\mathrm{O}_{2}$ in a barrel etcher with a pressure of 1 Torr for $3 \mathrm{~min}$ at $1000 \mathrm{~W}$ was used to remove the chromium instead. In Ref. 6, a linewidth of $200 \mathrm{~nm}$ was obtained. Our process yielded linewidths for the dipole antenna arms of $90 \mathrm{~nm}$, which can be seen in Fig. 4.

Next, the aluminum bond pads were fabricated on a 3 in. Si substrate using a bilayer resist profile as previously described. The bond pads were then exposed in positive resist in the e-beam writer at a beam current of $30 \mathrm{nA}$ with a dose of $200 \mu \mathrm{C} / \mathrm{cm}^{2}$. The wafer was developed in MIBK:IPA 1:1 for $2 \mathrm{~min}$. After development, an oxygen plasma etch was performed for $1 \mathrm{~min}$. Then a $100-\mathrm{nm}$-thick layer of aluminum was evaporated onto the substrate. The lift-off of the aluminum was carried out using methylene chloride.

The final step in the fabrication process was to fabricate the niobium detectors with dimensions of $1 \mu \mathrm{m} \times 0.25 \mu \mathrm{m}$, which allowed for maximum contact area between the detector and the antenna. First PMMA-MAA resist was spun on the wafer at $3000 \mathrm{rpm}$. The substrates were baked on a hot plate set to $170^{\circ} \mathrm{C}$ for 10 min to remove any solvents. Using an interferometer, the resist thickness was measured at 305 $\mathrm{nm}$. After the resist thickness was measured, the second layer was spun onto the substrates. For this layer PMMA was spun onto the substrates at $3500 \mathrm{rpm}$. Next the substrates were baked on a hot plate set to $170{ }^{\circ} \mathrm{C}$ for $10 \mathrm{~min}$. This yielded a total resist thickness of $460 \mathrm{~nm}$. The niobium detectors were written at $1 \mathrm{nA}$ with a dose of $370 \mu \mathrm{C} / \mathrm{cm}^{2}$. After exposure, the substrates were developed in MIBK:IPA 1:1 for $1 \mathrm{~min}$. After careful inspection to ensure proper development, the substrates were cleaned in oxygen plasma using a barrel etcher for $1 \mathrm{~min}$. Once the cleaning process was performed,

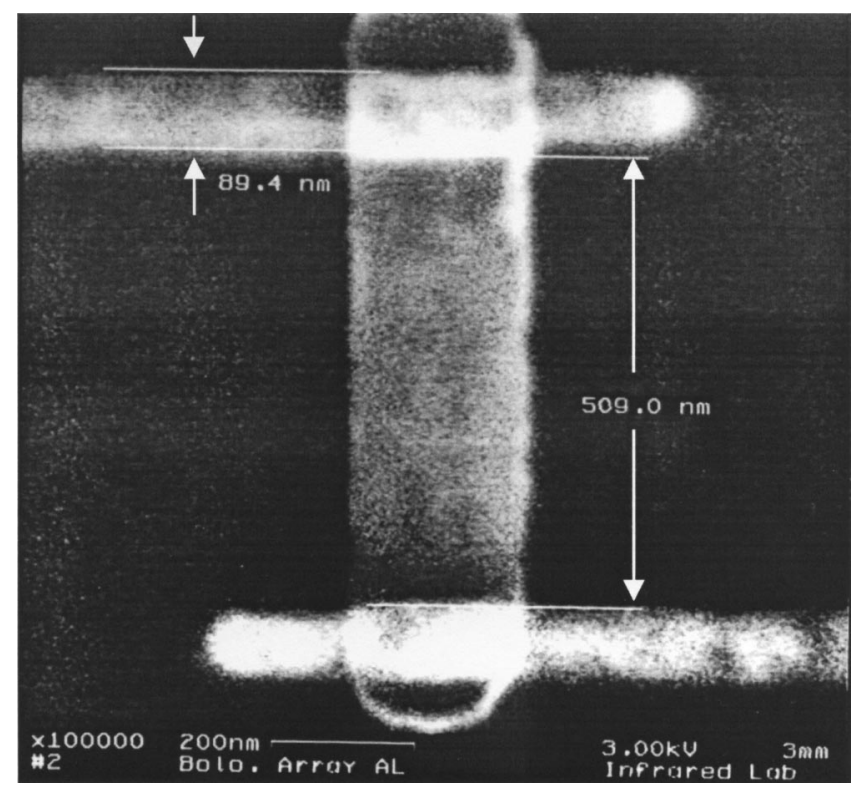

FIG. 4. SEM micrograph showing a resolution of $90 \mathrm{~nm}$ of the individual detector elements in the linear array. 
TABLE I. Pre-sputtering process.

\begin{tabular}{ll}
\hline \hline 1. & $\begin{array}{l}\text { Install niobium and titanium targets. } \\
\text { Close shutter over niobium target. } \\
\text { Attach power supply to niobium target. } \\
\text { 3. }\end{array}$ \\
& $\begin{array}{l}\text { Pump argon into the chamber. } \\
\text { Set pressure to } 3 \mathrm{mTorr}(21.1 \mathrm{sccm}) .\end{array}$ \\
4. & Apply $2 \mathrm{~kW}$ dc power. \\
5. & Keep shutter closed 5 min. \\
6. & Open shutter 10 min. \\
\hline \hline
\end{tabular}

the niobium was ready to be sputtered onto the substrate. After several experiments it was found that a pre-sputtering treatment of the chamber was required to obtain homogeneous devices. This treatment consisted of the following steps seen in Table I. Upon completion of this treatment process, the substrates were ready to be loaded into the chamber of the sputtering system. The substrates were loaded into the machine as soon as the chamber lid was raised enough to allow for clearance. This kept the base pressure as low as possible and limited the possibility of contamination of the sputtering system. The chamber was pumped down overnight to obtain the best possible vacuum, which was 1.8 $\times 10^{-7}$ Torr. Then the shutter was closed and titanium was sputtered for $10 \mathrm{~min}$. The exact processing requirements for this step are given in Table II. Titanium is a getter material, which means it absorbs oxygen and other gases once it is evaporated. This causes the pressure to become lower in the chamber, allowing a better quality film of niobium to be obtained. The chamber was allowed to cool for approximately $40 \mathrm{~min}$, which yielded a final pressure of 1.5 $\times 10^{-7}$ Torr. Then niobium was sputtered with the shutter closed for $5 \mathrm{~min}$. This was done to ensure that all the contaminants on the niobium target were removed. The shutter

TABLE II. Niobium sputtering process.

\begin{tabular}{|c|c|}
\hline 1. & $\begin{array}{l}\text { Close shutter over titanium target. } \\
\text { Attach power supply to titanium target. }\end{array}$ \\
\hline 2. & $\begin{array}{l}\text { Pump argon into the chamber. } \\
\text { Set pressure to } 1.6 \text { mTorr }(9.2 \mathrm{sccm}) \text {. }\end{array}$ \\
\hline 3. & Apply $2 \mathrm{~kW}$ dc power. \\
\hline 4. & Keep shutter closed $10 \mathrm{~min}$. \\
\hline 5. & Turn off dc power. Allow chamber to cool for $40 \mathrm{~min}$. \\
\hline 6. & $\begin{array}{l}\text { Close shutter over niobium target. } \\
\text { Attach power supply to niobium target. }\end{array}$ \\
\hline 7. & Set argon pressure to $3.1 \mathrm{mTorr}(21.1 \mathrm{sccm})$. \\
\hline 8. & Apply $2 \mathrm{~kW}$ dc power. \\
\hline 9. & Keep shutter closed for $5 \mathrm{~min}$. \\
\hline 10. & Open shutter for $5.1 \mathrm{~min}$. \\
\hline
\end{tabular}

was then opened and niobium was sputtered onto the substrates for $5.1 \mathrm{~min}$. This yielded approximately a 70-nmthick film of niobium. The substrates were allowed to cool for $30 \mathrm{~min}$ inside the chamber. Then the resist and excess niobium were removed with methylene chloride. SEM micrographs of the linear array, showing the results of the fabrication process, are shown in Fig. 1.

\section{SUMMARY}

The fabrication of a linear array of antenna-coupled microbolometer with critical linewidths of $90 \mathrm{~nm}$ has been demonstrated using electron beam lithography in conjunction with a RIE with chromium as a mask. There are two issues that must be addressed to further improve the performance of the linear array. The first is that the effective wavelength of $2.5 \mu \mathrm{m}$ from Ref. 6 needs to be more precisely determined, which will lead to an enhancement of the signal to noise ratio. The second is that a study on the antenna coupling between the individual antenna elements needs to be investigated to improve the performance of the array. This work demonstrates a unique method of fabrication for a linear array of antenna-coupled microbolometers with a resolution of $90 \mathrm{~nm}$. Improvements on this device could lead to the development of an uncooled two-dimensional focal plane array of antenna-coupled IR sensors.

\section{ACKNOWLEDGMENTS}

This work was performed in part at the Cornell Nanofabrication facility (a member of the National Nanofabrication Users Network), which is supported by the National Science Foundation under Grant No. ECS-9731293, Cornell University, and industrial affiliates. This material is based upon research supported by NASA Grant No. NAG5-10308.

${ }^{1}$ E. L. Dereniak and G. D. Boreman, Infrared Detectors and Systems (Wiley, New York, 1996), Chap. 9.

${ }^{2}$ C. Fumeaux, W. Herrmann, F. K. Kneubühl, and H. Rothuizen, Infrared Phys. 41, 123 (1998)

${ }^{3}$ I. Wilke, W. Herrmann, and F. K. Kneubühl, Appl. Phys. B: Lasers Opt. 58, 87 (1994).

${ }^{4}$ I. Wilke, Y. Oppliger, W. Herrmann, and F. K. Kneubühl, Appl. Phys. A: Solids Surf. 58, 329 (1994).

${ }^{5}$ M. E. MacDonald and E. Grossman, IEEE Trans. Microwave Theory Tech. Pt. 1, 893 (1995).

${ }^{6}$ C. Fumeaux, M. A. Gritz, I. Codreanu, W. L. Schaich, F. J. González, and G. Boreman, Infrared Phys. 41, 271 (2000).

${ }^{7}$ J. Alda, C. Fumeaux, M. A. Gritz, D. Spencer, and G. Boreman, Infrared Phys. 41, 1 (2000).

${ }^{8}$ M. Gritz, M. Metzler, J. Moser, D. Spencer, and G. Boreman, J. Vac. Sci. Technol. B 21, 332 (2003).

${ }^{9}$ P. Rai-Choudhury, Handbook of Microlithography, Micromachining, and Microfabrication, Vol. 1: Microlithography (SPIE, Bellingham, WA, 1997), Chap. 2.

${ }^{10}$ M. N. Webster, A. Tuinhout, B. Lochel, A. H. Verbruggen, J. Romijn, E. van der Drift, S. Radelaar, H. Jos, and P. M. A. Moors, Microelectron. Eng. 23, 441 (1994). 